\title{
Review
}

\section{Databases on biotechnology and biosafety of GMOs}

\author{
Giuliano DEGRASSI ${ }^{1, *}$, Nevena ALEXANDROVA ${ }^{1, * *}$ and Decio RIPANDELLI ${ }^{1}$ \\ ${ }^{1}$ Biosafety Unit, International Centre for Genetic Engineering and Biotechnology, Area Science Park, Padriciano 99,34012 Trieste, Italy
}

Due to the involvement of scientific, industrial, commercial and public sectors of society, the complexity of the issues concerning the safety of genetically modified organisms (GMOs) for the environment, agriculture, and human and animal health calls for a wide coverage of information. Accordingly, development of the field of biotechnology, along with concerns related to the fate of released GMOs, has led to a rapid development of tools for disseminating such information. As a result, there is a growing number of databases aimed at collecting and storing information related to GMOs. Most of the sites deal with information on environmental releases, field trials, transgenes and related sequences, regulations and legislation, risk assessment documents, and literature. Databases are mainly established and managed by scientific, national or international authorities, and are addressed towards scientists, government officials, policy makers, consumers, farmers, environmental groups and civil society representatives. This complexity can lead to an overlapping of information. The purpose of the present review is to analyse the relevant databases currently available on the web, providing comments on their vastly different information and on the structure of the sites pertaining to different users. A preliminary overview on the development of these sites during the last decade, at both the national and international level, is also provided.

Keywords: biosafety / biotechnology / databases / diffusion of information / environmental releases / field trials / genetically modified organisms / international organizations / patents / risk assessment / transgenes / websites

\section{INTRODUCTION}

The growing interest generated by some recent biotechnological applications has led to the development and release of genetically modified organisms (GMOs), crops in particular. This development has resulted in an increasing demand for information on different aspects of these biotechnological products, especially on the safety of the environmental release of GMOs and on the risks deriving from their use as food or feed. As a consequence, in the last decade a number of websites providing information on this matter have been created. This phenomenon can be easily verified when searching the web by using appropriate keywords such as "GMO", "biosafety" and "risk assessment". However, there are different types of information related to the problems concerning the use of GMOs, such as scientific and technical information, environmental, health and socioeconomic impacts, regulatory and legislative issues, field trials and commercial releases, risk assessment, monitoring, traceability and labelling. On the other hand, there are also several categories of professional and nonprofessional individuals interested in acquiring information on biotechnology and biosafety of GMOs, including scientists, governmental officers and policy makers, farmers, consumers and environmentalists. The situation is even more complicated if we consider other parameters such as quality, availability and accessibility of the information. In particular, validation of information contained in databases represents an important issue, affecting the reliability and impact of the data retrieved, and therefore the usefulness of the database itself. Further, the

\footnotetext{
* Corresponding author:

Tel.: +39-040-3757317; fax: +39-040-226555; e-mail: degrassi@icgeb.org

** Present address: Institute of Genetic Engineering, National Centre of Agricultural Sciences, 2232 Kostinbrod, Bulgaria
} 


\section{G. Degrassi et al.}

differences between the sources providing information related to research, development, application and commercialisation of biotechnological products, and those specifically aimed at providing information on issues concerning the safety of biotechnological products, in particular GMOs, should be highlighted. In addition, risk assessment requires widely different information, not only specific biosafety data, but also a biotechnological background.

In summary, there are several factors that explain the increasing role of information-sharing and the growing number of available information tools and databases in biotechnology:

(a) the multidisciplinary feature of biosafety, and the complexity of risk analysis (commonly recognized as having three components - risk assessment, risk management and risk communication) and of policymaking (setting up biosafety frameworks, taking informed decisions, etc.) define the need to access as many information sources as possible;

(b) involvement of different stakeholders in the process of achieving safety from products of modern biotechnology: risk assessors, risk managers, consumers, the academic community, industry and environmentalists;

(c) the greater role of risk communication as an interactive exchange of information and opinions among the stakeholders; more requirements for publicity and public participation in biosafety issues;

(d) the need for countries to fulfill their obligations under several international treaties. This includes the Cartagena Protocol on Biosafety (CPB), which enters into force in 2003. It focuses primarily on the transboundary movements of living modified organisms (LMOs), whose import/export procedures require extensive and easily accessible information. The aim of the CPB is "to ensure an adequate level of protection in the field of the safe transfer, handling and use of living modified organisms", and some key articles (Art. 10 and 11) specifically refer to the information necessary in the decision-making procedure for the approval of the transboundary movement of LMOs.

This review focuses on the current situation of databases in the field of biosafety of modern biotechnology. We have identified, selected and discussed the information contained in many useful databases, providing links and a background on their utility in order to facilitate access to the appropriate information for different stakeholders dealing with the safety of GMOs. Two methods were used for identifying and selecting websites: (a) searching in bibliographic databases, namely $\mathrm{CAB}$
Abstracts and AgBiotechNet, using keywords such as "GMO", "database", "information" and "biosafety"; and (b) navigating the web using these same keywords and selecting the sites according to (i) type of information; (ii) state of updating; and (iii) frequency of links to the database in other websites dealing with biotechnology and biosafety.

Based on these two search procedures, the main text of this review has been divided in two main parts: the first contains information on some sites developed to store detailed or general data on specific subjects, related to modern biotechnology and biosafety. These sites, identified through bibliographical databases, are the few that have been reported and analysed in scientific publications. The second part provides the following group of databases:

(a) databases developed and managed through international organizations' initiatives, aimed at either supporting developing countries, implementing international treaties, or strengthening, harmonizing and coordinating common efforts in disseminating information and protecting the environment and human health;

(b) national databases predominantly set up in view of national legislation;

(c) other databases containing general, non-specific information on biosafety of GMOs that are potentially useful to risk assessors, scientists involved in biosafety research and other stakeholders.

\section{DATABASES: A TOOL FOR DISSEMINATING INFORMATION}

Most documents produced in and about biotechnology and biosafety of GMOs are available on the Internet, which is widely considered the main provider of information. The most relevant of the considerable number of websites to consult are briefly described at the Information System for Biotechnology (ISB) website, www.nbiap.vt.edu/othersites/indexlinksdblevel1.cfm. This site contains links to the annotated websites pertaining to agricultural and environmental biotechnology. Some of these sites are true databases aimed at storing data, documents and other information, with a retrieval system allowing an easy and efficient reading of data from the storage device, while others simply contain general information.

A database is a collection of computer data that can be automatically retrieved or manipulated, and which is intended to acquire, allow access to, expand, maintain, manage and catalogue information. The system consists 
of hardware, software, data and users, requiring a management system that permits databases to be defined, filled with data, and manipulated through queries and updates (http://phoenix.marymount.edu/ bhoffman/DB/ DBTerminology.html).

The vast information contained in databases relevant to biosafety issues related to the use of new biotechnology products such as GMOs is both general and very specific. It includes detailed knowledge acquired on genetic elements (scientific and technical data on proteins, DNA sequences and profiles, germplasms and genetic maps), general data on environmental releases, specific information on food safety and allergenicity, and biological and genetic knowledge on crops currently modified by modern biotechnology. Other databases specifically include compilations of state regulations on biosafety or reference standards for quality assurance of biotechnologybased measurements. In the last ten years several published reports provided information on actions taken to develop databases relevant for biotechnology and safety assessment of GMOs. They also aimed at satisfying the need for a rationale and well-targeted sourcing of information. Some of these initiatives, reported and discussed in published articles, are described and listed below.

Particularly abundant are the sources of information related to biosafety regulations. No other type of documents has benefited as much from the ease of search and retrieval offered by Internet as government regulations. Academic and industrial biotechnologists can take advantage of the websites of various national and international organizations, institutions, and authorities that host constantly changing regulations. Some useful sites have been recently reviewed, with descriptions and comments on the information provided (Francisco, 1999).

Genetically modified organisms are plants or animals in which techniques of recombinant DNA had been used to introduce, remove or modify specific parts of the genome of the organism. The transformation process requires several genetic elements such as transgenes, marker genes, promoters and terminators. Due to regulations on food contamination and labelling, and the need to monitor GMOs in the environment, assessing the presence of DNA from GMOs has become important. Concern over the possible transfer of genetic markers from transgenic plants to micro-organisms has also increased the need for information on the nucleotide sequence of these genes. Detection of target DNA, instead of the encoding protein, is commonly used and achieved by PCR, (Ahmed, 2002), which requires information on the sequence of the correspondent genetic elements. In one of the first databases reported aimed at providing this kind of information, 16 of the most commonly used selectable markers, reporter genes, promoters and terminators used for genetic transformation of plants, together with nucleotide sequences, encoded polypeptides, sequence features and restriction maps were collected. Other data included were length, transcription and translation start and stop codons, putative glycosylation sites, multiple cloning sites, encoded polypeptide sizes and isoelectric point (Croy, 1993). The frequent changes of certain genetic determinant sequences before the cloning process, which are usually followed by the patenting of the modified gene and its application, represents a limitation in the use of this resource. However, the importance of this kind of information is confirmed by another database, Gene Files, developed recently as part of the Biosafety Files (Tab. 1). This latter system was established in consideration of the need to access scientifically verified and non-biased biosafety data, in particular for the risk assessment that precedes the release of GMOs. The system is hosted at http://www.biosafety.nl/ and described by Louwaars et al. (2002). The Biosafety files, whose aim is to contribute to risk assessment capacity, currently consists of three interlinked databases, each containing a different type of essential information for the competent authorities called to approve the introduction of GMOs in the environment and/or in the food chain: Gene Files, Botanical Files and Food Files. Gene Files is a database with generic information on genes, promoters and selection sequences. It provides a clear basis for analysis as a source of synonyms and primary information on relevant sequences. Food Files contains information on food safety aspects of genetically modified crops, including composition analysis, animal tests, potential allergenicity of novel proteins, and stability of foreign DNA and proteins. Combining this generic safety data with local consumption patterns will allow for the assessment of risks at a local level. Botanical Files provides data on the possibility of a crop to outcross with wild and weed relatives, conventional landraces, and other varieties of the same crop plant. The concept of Botanical Files was also reviewed by Conner et al. (2003). It is based on fivecode gene flow indices, which include the factors affecting the impact of the release; each code is subdivided in seven levels of potential risk. Botanical files should be established and applied at the regional level.

The potential ecological impact of field and/or commercial releases of GM crops is one of the main concerns deriving from the use of modern biotechnology. 


\section{G. Degrassi et al.}

Table 1. Examples of useful databases with potential application in biosafety research and regulations: Scientific information sites.

\begin{tabular}{llll}
\hline \hline Search for: & URL & Description & Status \\
\hline $\begin{array}{l}\text { Genes, transgenes, gene } \\
\text { elements }\end{array}$ & $\begin{array}{l}\text { Specific biosafety database that } \\
\text { provides data on the origin of the } \\
\text { species of the inserted DNA, the } \\
\end{array}$ & $\begin{array}{l}\text { Ongoing } \\
\text { biological function of the gene } \\
\text { product, the possible substrates and } \\
\text { their metabolites, and the } \\
\text { physiological impact to the host. }\end{array}$ \\
& &
\end{tabular}

Toxins

Allergens

Methods for detection, identification and risk assessment

Biological data
Canadian Forest Service Specificity database: http://www.glfc.forestry.ca/bacillus/

NCFST food allergy database: http://www.iit.edu/ sgendel/

JRC "validated methods" database: http://biotech.jrc.it/

FAO "Glossary of biotechnology for food and agriculture": http://www.fao.org/biotech/index.asp

IT IS (Integrated Taxonomic Information System): http://sis.agr.gc.ca/pls/itisca/ taxaget?p_if $x=a a f c$

"Tree of life project": http://www.tolweb.org/tree/ phylogeny.html

OECD "Consensus documents": http://www.oecd.org/EN/document/ 0, EN-document-528-nodirectorateno-27-9461-32,00.html

"Botanical files": http://www.biosafety.nl/
$B t$ toxin specificity database.

Fully operational

Food allergen and non-food allergen sequences; wheat gluten sequences.

Provides: (i) General information on the GMO and the method (i.e. matrix, producer company, plant species, etc.); (ii) specific information on the proficiency of the method and its validation status (i.e. specificity, sensitivity, LOD, linearity, working range, etc.); and (iii) technical information (i.e. primer sequences, amplicon length, apparatus, control primer sequences, use of certified reference materials, method of amplicon verification, etc.).

Glossary of terms and definitions in biotechnology and biosafety.

Searching mechanism for common and scientific names of organisms.

Fully operational

Phylogenetic information.

Fully operational

Technical information on the regulatory assessment of products of biotechnology that focuses on the biology of organisms (plants, trees or micro-organisms) or introduced novel traits.

Data on geographical dissemination of native plant species and the ability to outcross with given GM crop. 
Review: Databases on biosafety of GMOs

Table 1. Continued.

\begin{tabular}{|c|c|c|c|}
\hline Search for: & URL & Description & Status \\
\hline \multirow[t]{4}{*}{ Environmental releases } & $\begin{array}{l}\text { OECD's Database of Field Trials: } \\
\text { http://www.olis.oecd.org/biotrack.nsf }\end{array}$ & $\begin{array}{l}\text { Records of field trials of GMOs that } \\
\text { have taken place in OECD Member } \\
\text { Countries. It also includes data from } \\
\text { other countries provided through } \\
\text { UNIDO's BINAS. }\end{array}$ & Fully operational \\
\hline & $\begin{array}{l}\text { JRC “Deliberate Field Trials"/EU } \\
\text { database: } \\
\text { http://biotech.jrc.it/ }\end{array}$ & $\begin{array}{l}\text { Deliberate releases in EU searched by } \\
\text { country and species. }\end{array}$ & Fully operational \\
\hline & $\begin{array}{l}\text { Belgian Biosafety Server-Deliberate } \\
\text { release of GMOs for experimental } \\
\text { purposes in Belgium: } \\
\text { http://www.biosafety.be/ } \\
\text { HomePage.html }\end{array}$ & $\begin{array}{l}\text { Contains data for the release of GM } \\
\text { plants, micro-organisms and } \\
\text { transgenic animals for experimental } \\
\text { purposes. }\end{array}$ & Fully operational \\
\hline & $\begin{array}{l}\text { ISB/ Field Test Releases in the USA: } \\
\text { http://www.isb.vt.edu/CFDOCS/ } \\
\text { fieldtests1.cfm }\end{array}$ & $\begin{array}{l}\text { Database for the field test releases in } \\
\text { USA; an advanced searching } \\
\text { mechanism is provided. }\end{array}$ & Fully operational \\
\hline \multirow[t]{2}{*}{ Food safety } & $\begin{array}{l}\text { "Food files" database: } \\
\text { http://www.biosafety.nl/ }\end{array}$ & $\begin{array}{l}\text { This includes data on safety tests } \\
\text { related to the food- and feed-uses of } \\
\text { the GM crop; a list of food products } \\
\text { derived from the GM crop; data on } \\
\text { feed-related aspects; an overview on } \\
\text { approvals for field trials and } \\
\text { commercial application. }\end{array}$ & Ongoing \\
\hline & $\begin{array}{l}\text { Prototype of FAO's "International } \\
\text { portal for Food safety, animal and } \\
\text { plant health": } \\
\text { http://193.43.36.96/Biosec/En/ } \\
\text { default.jsp }\end{array}$ & $\begin{array}{l}\text { An access point for official national } \\
\text { and international information relating } \\
\text { to bioprotection, the risks associated } \\
\text { with agriculture (including fisheries } \\
\text { and forestry) and food production. }\end{array}$ & Starting \\
\hline \multirow[t]{3}{*}{ Publications } & $\begin{array}{l}\text { ICGEB's bibliographic database: } \\
\text { http://www.icgeb.org/ bsafesrv/ } \\
\text { bsfdata1.htm }\end{array}$ & $\begin{array}{l}\text { Scientific bibliographic collection of } \\
\text { studies on "Biosafety and Risk } \\
\text { assessment in biotechnology". The } \\
\text { database contains scientific articles } \\
\text { published in international scientific } \\
\text { journals from } 1990 \text { onwards, selected } \\
\text { and classified for the main topics of } \\
\text { concern for the environmental release } \\
\text { of GMOs. }\end{array}$ & Fully operational \\
\hline & $\begin{array}{l}\text { Agbios "Essential Biosafety: } \\
\text { Bibliography database" } \\
\text { http://www.agbios.com/biblio.php }\end{array}$ & $\begin{array}{l}\text { Citations relevant to the } \\
\text { environmental, human food, and } \\
\text { livestock feed safety of GM crops. }\end{array}$ & Fully operational \\
\hline & $\begin{array}{l}\text { PubMed: } \\
\text { http://www4.ncbi.nlm.nih.gov/entrez/ } \\
\text { query.fcgi }\end{array}$ & $\begin{array}{l}\text { A service of the USA National } \\
\text { Library of Medicine, which provides } \\
\text { access to over } 12 \text { million MEDLINE } \\
\text { citations and additional life science } \\
\text { journals. }\end{array}$ & Fully operational \\
\hline
\end{tabular}




\section{G. Degrassi et al.}

In 1991, the lack of a global information resource on releases to the environment encouraged the United Nation Environmental Programme (UNEP) to invite Microbial Strain Data Network (MSDN) to organize a workshop to discuss the needs and specifications for a worldwide information system dealing with the environmental release of non-indigenous, novel, or genetically modified organisms. An outgrowth of this workshop was the Information Resource for the Release of Organisms into the Environment (IRRO), which aimed at providing an international, non-profit-making, free information resource for monitoring the introduction of non-modified and genetically modified organisms into the environment. IRRO bears no regulatory or advisory mission but acts as a neutral information service. The background and objectives of the initiative were analysed by Kirsop (1993). Information sources are linked together by electronic gateways with common interfaces, while data is compiled in past releases, biosystematics and the physiology of organisms, the ecosystem of the release site, expected ecological integration, and regulatory issues. Separate databases such as BioTrack from the Organisation for Economic Co-operation and Development (OECD), International Institute of Biological Control (BIOCAT), Code of Practice from United Nations Industrial Development Organization (UNIDO), directives and guidelines from European Community (EC) and the EC list of competent authorities were originally integrated on IRRO's system. The result is a unique collection of databases covering microbiology, biotechnology and biodiversity, and holding information about environmental releases (http://www.irptc.unep.ch/).

BioSearch is another database aimed at collecting and storing information on field releases of genetically transformed plants in different countries in Europe from 1992 to 1995 . It was developed in Germany by Biologische Bundesanstalt für Land- und Forstwirtschaft (http:// www.bba.de/gentech/genright.htm\#Menue). It was used to produce tables with numbers of field releases by country, crop and genetically modified characteristic (Landsmann and Shah, 1995). Although the database outline and tables are well designed and simple to consult, the website is in German only, except for an English glossary, which limits the accessibility of the information.

A limited number of crops have been genetically modified and released into the environment so far. Past discussions concerned creating specific databases for these crops, including a proposal to develop internationally accessible databases of genes transferred to crops and tested in the field. For example, the recent rapid progress in transferring foreign genes for expression in rice has been widely recognized, as well as the need for an international database allowing information exchange on transgenic rice plants between molecular biologists, plant breeders, company researchers and government regulators (Havukkala, 1996). Developing such a database that would also include information from the rice genome mapping would be a useful tool, not only for further development and evaluation of transgenic rice plants, but also monitoring. As a result of this need, the number of databases covering the biotechnology of this crop has become considerable, as can be seen in the website http://www.grs.nig.ac.jp/WGR/link/link_Rice_e.html, which lists the most important sites.

Estimation of risks deriving from the environmental release of GMOs often requires a decision support system. The design and construction of such a system aimed at providing appropriate information to decision-makers and researchers has been analysed and described, together with the modules and the methodologies to be applied for efficient use in planning experiments (Gliddon et al., 1997). The website http://binas.unido.org/dtreeb/ hosts a decision support system for the safety assessment of genetically modified crop plants. Another system was developed by the USA Department of Agriculture (USDA) as a tool for assessing and managing risks posed by the research conducted with GM fish and shellfish referring to the Performance Standards elaborated by the USDA Agricultural Biotechnology Research Advisory Committee. To facilitate the use of Performance Standards, a computer-based decision support tool has been developed, consisting of a program that automatically generates a trace of the user's path through the decision questions, thereby automating the completion of a worksheet (http://www.isb.vt.edu/perfstands/perfstands1.cfm).

We have seen some examples of databases providing information on genetic elements used in the process of genetic modification of organisms, on releases of modified organisms into the environment, and on the risks deriving from the release of GMOs. One of the risks that needs to be assessed is the potential allergenicity of proteins derived from GMOs. An important tool in the process of risk assessment of such food is represented by two databases of allergen sequences (food allergens and non-food allergens) that have been constructed using information from three large reference protein sequence databases (GenePept, release 94; Protein Identification Resource, release 48; SwissProt, release 33) for assessing potential allergenicity of proteins introduced into transgenic food. Each reference database has been searched for the identification of allergen sequences 
using different strategies of amino acid sequence alignment (Gendel, 1998a). Identified allergen sequences have been compared to homologous sequences in other databases to identify equivalent sequences and allelic variants. According to this information, non-redundant allergen sequence databases have been constructed, containing all the currently available sequence variants for food and non-food allergens (Tab. 1). Updating of these databases is carried out periodically as new allergen sequences become available or as new proteins are identified as allergens. The database is available at http:// www.iit.edu/ sgendel/ (Gendel, 1998b).

Several Bacillus thuringiensis (Bt) insecticidal proteins are commonly expressed in insect-resistant GM crops such as corn and cotton, causing concern over their potential allergenicity. The importance of allergen databases was evaluated by a test to assess the potential allergenicity of six $B t$ insecticidal proteins, three common non-allergenic food proteins and 50 randomly selected maize proteins using current bioinformatic tools and a database of allergens and gliadins (Hileman et al., 2002). The evaluation of proteins by the FASTA algorithm resulted in the most accurate predictions of clinically relevant cross-reactive allergens. No significant sequence similarities or matches of eight contiguous amino acids were found with the $B t$ or food proteins, while 41 of the 50 maize proteins matched at least one allergen with six contiguous identical amino acids. It was concluded that an additional search for matches of an eight amino acid window may provide an added margin of safety when assessing the allergenicity of a protein, while searching for matches of a six amino acid window often results in random, irrelevant matches.

All the databases cited above show evidence of the many initiatives originating out of the need to develop tools for risk assessment and information-sharing on different aspects of GMOs and biosafety among stakeholders. This is further confirmed by the following actions taken described below.

\section{DATABASES FROM INTERNATIONAL ORGANIZATIONS}

The concept of biosafety in relation to the introduction and release of GMOs includes three main sectors, namely human and animal health, environment conservation and food safety. Biological and environmental risks associated with GMOs are managed by governments through policy and regulatory frameworks that often require efficient and updated international standards supporting appropriate national actions. International policy and regulatory frameworks for environmental, agricultural and food biosafety are complex and include risk analysis, monitoring, standard setting, capacitybuilding and exchange of information. Several online initiatives seek to address access to information on biosafety, with special regard to those that have been already verified from a scientific point of view. This is a field where international cooperation is developing fast. Due to the need for a coordinated and harmonized effort, initiatives tend to be organized in sectors. Several databases developed by international organizations actively involved in biosafety and risk assessment could therefore represent references for national authorities. Some general information on the features of databases developed is provided below.

We have seen two different databases developed for recording releases of GMOs into the environment and/or field trials, IRRO and BioSearch. There are national databases that share this aim, but they are not coordinated with others. International organizations could play an important role in collecting and/or harmonizing (making systems similar or consistent with each other) information from different countries. The Harmonization of Regulatory Oversight in Biotechnology established in 19971999 is an OECD Programme of Work. Its goal is to promote international harmonization in biotechnology to ensure that environmental health and safety aspects are properly evaluated. The most relevant initiative in this programme is the development of OECD's online databases of (i) products of biotechnology (http:// www.olis.oecd.org/bioprod.nsf, Tab. 2) and (ii) field trials (BioTrack) (http://www.olis.oecd.org/biotrack.nsf; Tab. 1), which includes field trial records of GMOs that have taken place in OECD Member Countries and data from other countries provided through UNIDO's Biosafety Information Network and Advisory Service (BINAS). BINAS is a service of UNIDO that monitors global developments in regulatory issues in biotechnology (http://binas.unido.org/binas/regs.php). It contains relevant laws and regulations from responsible ministries, agencies, and contact points in OECD and UNIDO countries. BINAS works together with OECD towards a common resource on harmonization in biotechnology. A joint website, BIOBIN (http://www1.oecd.org/ehs/ BIOBIN/) is a tool that allows navigation between OECD's BioTrack Online and UNIDO's BINAS.

Harmonization and coordination of initiatives in biotechnology and biosafety are important driving forces behind activities of international organizations dealing with regulatory aspects, dissemination of information and capacity-building in the context of protecting the 


\section{G. Degrassi et al.}

Table 2. Examples of useful databases with potential application in biosafety research and regulations: International regulatory databases.

\begin{tabular}{lll}
\hline \hline URL & Description & Status \\
\hline Biosafety Clearing-House Pilot Phase: & Central portal and central database containing & Pilot Phase \\
http://bch.biodiv.org/Pilot/Home.aspx & specific information on biosafety as required \\
& by the Biosafety protocol - laws, regulations, \\
& guidelines and agreements, decisions under \\
& AIA and FFP procedures; risk assessments; \\
& capacity-building projects and opportunities \\
& and related links.
\end{tabular}

OECD Product database:

http://www.olis.oecd.org/bioprod.nsf

ICGEB's Risk Assessment Searching Mechanism (RASM):

http://www.icgeb.org/ bsafesrv/rasm.html

Biotechnology Policy Documents of FAO Members: http://www.fao.org/biotech/country.asp
Database for products derived using Modern Biotechnology that have been approved for commercialisation or are in the process of being approved for commercialisation.

An index of the official and technical documents on risk assessment of LMOs authored by biosafety competent national authorities.

This brings together biotechnology policy documents from FAO members; it comprises only national and regional policy documents, which are available on the web. The title, date and language(s) of the documents, as well as an indication of their size are provided. environment and human health from products of modern biotechnology. This need of harmonization and coordination is mainly due to different strategies and standards adopted at the national level and different infrastructures available in developed and developing countries.

The Convention on Biological Diversity (CBD) is the major outcome of the 1992 Earth Summit in Rio de Janeiro, where most of the world's governments set commitments for "ensuring that we leave a healthy and viable world for future generations", promoting strategies for "sustainable development". The CBD establishes three main goals: the conservation of biological diversity, the sustainable use of its components, and the fair and equitable sharing of the benefits from the use of genetic resources. Within CBD activities, a clearing-house mechanism was established to promote international technical and scientific cooperation in the conservation and sustainable use of biological diversity (http://www.biodiv.org/ chm/default.aspx). After the adoption of the CPB in 2000 and in accordance with its Article 20 (http://www.biodiv.org/biosafety/protocol.asp), a Biosafety ClearingHouse $(\mathrm{BCH})$ was launched as part of the clearing-house mechanism. The aims of the $\mathrm{BCH}$ are to facilitate the exchange of scientific, technical, environmental and legal information on and experience with LMOs, and to assist the Parties in implementing the Protocol. According to the $\mathrm{BCH}$ 's need to be operational by the time the Protocol enters into force, the $\mathrm{BCH}$ started with a Pilot Phase (http://bch.biodiv.org/Pilot/Home.aspx) consisting of a central portal and a central database ensuring the inclusion of and access to relevant data from countries that ratified the Protocol, as well as from Parties without a national database or national electronic infrastructure (Tab. 2). The BCH Pilot Phase also provides access to searchable indexes facilitating decision-making under the Advanced Informed Agreement (AIA Procedure, Art. 10) for the approval of the transboundary movement of LMOs intended for direct use as food, feed or for processing (FFP procedures; Art. 11). The following information can be searched within the $\mathrm{BCH}$ website: national contacts, laws and regulations, decision information including risk assessment documents, capacitybuilding initiatives and other biosafety websites. Other than providing data, the $\mathrm{BCH}$ has to enable governments to provide information through the "Management center" item of the central portal, and to access available information for the decision-making process through the central database. National focal points have access to the central portal for entering, supplementing and updating national information that must be first screened and 
verified before being made available internationally. The final goal is to promote the development of national databases for national and international uses in a harmonized and coordinated manner through the $\mathrm{BCH}$. Two of the problems to be solved in this effort are the interoperability of national systems with the central portal and different languages.

There are other sources of data and information that have been taken into account by the $\mathrm{BCH}$ and made available through the central portal. This is the result of partnerships such as the OECD/UNIDO with "mandatory information" or the International Center for Genetic Engineering and Biotechnology (ICGEB) with "nonmandatory" information. (See http://bch.biodiv.org/ Pilot/News/Note1.aspx for details.) Access to the existing information systems such as the OECD/UNIDO and the ICGEB databases is provided through the $\mathrm{BCH}$ Pilot Phase, following the recommendation of the Intergovernmental Committee for the Cartagena Protocol (ICCP) to the Executive Secretariat.

The ICGEB database is a scientific bibliographic database collecting studies on biosafety and risk assessment in biotechnology. It can be accessed through the website http://www.icgeb.org/ bsafesrv/bsfdata1.htm. It is updated monthly and contains both full references to and abstracts on scientific articles published in international scientific journals from 1990 onwards (Tab. 1). These articles are classified according to the main subject(s) of the publication and potential risks related to the environmental release of GMOs. Such risks include those for animal and human health, the environment, and agriculture. There are risks of interaction with non-target organisms, risks of gene transfer, and general risks (refer to the "topics of concern", http://www.icgeb.org/ $\sim$ bsafesrv/bsfconc.htm). Articles are selected by using specific keywords related to the issues of biosafety and GMOs, and extracted from the internationally renowned applied life sciences database CAB ABSTRACTS ${ }^{[\mathrm{tm}]}$, the main collection of data on biosafety that is not focused on human health. It has also been chosen to avoid duplication with PubMed.

ICGEB has also developed a Risk Assessment Searching Mechanism (http://www.icgeb.org/ bsafesrv/ rasm.html; Tab. 2) with the objective of providing a tool for the decision-making process according to Article 10 of the CPB. This searching mechanism allows access to official documents on risk assessment related to the environmental release of GM crops in different countries and complements other existing databases. The information provided originates from official governmental sources regarding both approved and non-approved GMOs. The searching mechanism plays a role in data maintenance including the temporary storage of data not yet available on the Web due to lack of electronic infrastructure in some countries. It therefore aims at ensuring the completeness of the information available worldwide. It is complementary to and interlinked with other existing database such as USDA, OECD, European Bioinformatics Institute (EMBL) and SwissProt. Risk assessment documents can be retrieved through several selection criteria: taxonomical classification of the GMO, GMO or company identifier, trait, gene, year, country, responsible authority, document title and type of risk assessment document.

The aim of disseminating or sharing information and data produced worldwide may be limited by inappropriate terminology that often hampers efficient communication and discussions at the intergovernmental level. In its response to the problem, the Food and Agriculture Organization of the United Nations (FAO), active in disseminating information on the safety of agricultural products derived by modern biotechnology, developed a useful tool for acquiring general information and consolidated terminology in biotechnology - the "FAO Glossary of Biotechnology for Food and Agriculture" (Tab. 1). The "Glossary" (http://www.fao.org/biotech/ index_glossary.asp) is a searchable tool providing a comprehensive and accessible list of terms and acronyms used regularly in biotechnology in food and agriculture. With its 3196 terms and related definitions, it is a convenient reference source for researchers, students and technicians.

FAO is also involved in other projects aimed at disseminating and sharing information on food safety, animal and plant health from the scientific and regulatory sectors, according to its mandate and in collaboration with other relevant international agencies. Through its portal, a central Internet-based mechanism for the exchange of information on national and international regulatory and policy frameworks is in progress, to which national and international agencies will contribute (contributors involved retaining data ownership). Also anticipated are a tool kit of information resources including: established methodologies for risk analysis; risk assessments carried out and risk management decision-making processes at the national level; specific risk assessments provided by FAO/WHO expert consultations; alert-warning systems; information on capacity building, and access to other sources and links.

Another ongoing FAO project seeks to bring together national and regional biotechnology policy documents of the FAO Member States (183 Member States 


\section{G. Degrassi et al.}

plus 1 Member Organization, the EU). At present, 17 documents issued by 11 countries are searchable on http://www.fao.org/biotech/country.asp (Tab. 2).

More recently, FAO has been developing an inventory on the state of biotechnology in developing countries. This aims at setting up a reliable source of information on the adoption and application of different biotechnologies in the developing world, and a decisionmaking tool in forming collaborative research efforts in biotechnology. To make the inventory as dynamic and up-to-date as possible, it has been converted into an online searchable database that will be regularly verified and updated directly at http://www.fao.org/biotech/ inventory_admin/default.asp by biotechnology national focal points. Records can be searched using a combination of selected fields such as product or technology, trait or technique used, species, country, region, institution, and status of the development process (i.e. the experimental phase, field trials, commercialisation). The database collects and stores information not only on GMOs, but also on other biotechnological products such as those obtained by micropropagation, in vitro regeneration, embryo rescue, RFLP (random amplified polymorphic DNA), AFLP (amplified fragment length polymorphism), and in vitro germplasm conservation and exchange.

A summary of databases mentioned in this section and other important databases can be found in Tables 1 and 2 .

\section{NATIONAL DATABASES}

As a result of the increasing economical importance of biotechnology products, growing public interest for these products is observed at the national level. Consequently, industrialized and developing countries have implemented biosafety policies and procedures to ensure their safe use. These protective measures are implemented through biosafety systems that provide a mechanism for making informed decisions. Moreover, both governmental and non-governmental agencies and organizations put efforts into communicating their activities to the public on environmental and food safety through Internet-based mechanisms. Several national and governmental databases have been developed accordingly. Public perceptions of and concerns over risks for the environment and human health deriving from the release of GMOs and their use as food and feed are the driving forces towards disseminating information. Countries where GMOs have been released into the environment or where the authorization for their release is under evaluation or field trials are in progress have set up specific websites for accessing relevant information on the state of the approval processes, the location of the field trials sites, updated regulatory frameworks and legislation, among others. Data on the total surface cultivated with GMOs worldwide in 2002 show that the USA represents $66 \%$ of the total, Argentina 23\%, Canada 6\%, and China 4\%, (James, 2002). However, many other countries have released GMOs into the environment as shown by field trials in progress. In addition to the releases of GMOs and their potential adverse effects on the environment, the use of GMO derivatives in food and feed is generating public concern. Another type of available information in these websites regards decisions on novel food, together with the regulations and guidelines for the safety assessment used in the decision process. The following are some examples of national websites dealing with biosafety in relation to (i) the environmental release of GMOs and (ii) the approval of novel food.

Data on environmental releases can be stored and organized either in tables or lists, as in most of the following websites, or in true databases such as the Belgian Biosafety Server database, where data can be retrieved according to year of approval, organism, trait inserted and institute or company responsible for the release. The Belgian Biosafety Server is a website that focuses essentially on the scientific and regulatory aspects of biological safety of human activities carried out using pathogens and/or GMOs. The information provided concerns both research and development (R\&D) and market parameters of the agro-food/feed, pharmaceutical, medical, veterinary, agronomic and environmental sectors, as well as local and international regulations, guidelines and agencies involved in biological safety including its biodiversity dimension. It is organized into three sections, each providing regulatory and scientific information on biosafety in Belgium, the European Union (EU), and other countries, respectively (http://www.biosafety.be/HomePage.html). It has been developed according to the $\mathrm{BCH}$ guidelines for participation in the international information procedure, in view of the ratification of the CPB. The authorization procedure for the deliberate release of GMOs for experimental purposes can be followed. Moreover, after the submission of a notification, a summary of the information contained is made available to the public for consultation on the Joint Research Centre of the European Commission website, http:// gmoinfo.jrc.it/. The purpose of this website is not only to publish information, but also to receive comments from the public on notification of approvals on deliberate field 
trials or on GMOs placed on the market according to Directive 2001/18/EC of the European Parliament. All the releases from European countries notified under this Directive can be consulted on this website.

Argentina is the second country in the world for its area cultivated with GMOs. Its situation regarding the releases referring to either greenhouse testing or field trials can be followed at the CONABIA website, http://www.sagpya.mecon.ar/http-hsi/english/conabia/ liuk.HTM. Releases are divided into tables based on the year of approval, which provide details on company/ institute, crop plant, trait and application (laboratory, greenhouse or field). The national procedure for approval is also described and includes the so-called "flexibilisation" permit, for which the applicant can apply as soon as at least one release into the environment has been approved and the safety of the GMO has been demonstrated. This permit allows the applicant to perform future releases by merely providing notification on the sown area and date, site of release and date of harvest. Two lists are available, one of GM crops approved for "flexibilisation" and one for commercialization. However, in order for commercialisation approval to be granted, the transgenic material must comply with the requirements of the National Service of Agrifood Health and Quality (SENASA), which is responsible for the safe consumption of all feeds and foodstuffs and must pass the technical review of the National Division of Agrifood Markets of the Secretariat, which assesses the convenience of marketing the GMO. This assessment seeks to avoid any potential negative impact on Argentine exports.

In Australia, the Gene Technology Act 2000, which came into force on 21 June 2001, introduces a national scheme for regulating GMOs. This scheme aims at protecting the health and safety of Australians and their environment by identifying risks posed by or as a result of gene technology, and at managing those risks by regulating certain GMOs. These activities are performed by the Office of the Gene Technology Regulator and can be observed on the website http://www.health.gov.au/ogtr/ index.htm. In addition to the usual records of releases and related information, the site offers other information choices, such as field trial sites, post-harvest monitoring, protocols and compliance, with the purpose of providing the Australian public with ready access to information on all GMOs and GM products being used in the country. An interactive map shows the location of field trial sites on the national territory, providing access to individual licensed sites through licence numbers. More detailed regional maps are included, allowing farmers to be aware of the GM crops cultivated in proximity of their fields. In addition, there are records of the sites undergoing postharvest monitoring, a sort of control on the effects of GM crops cultivation on crop fields.

Several national authorities have adopted disseminating information on regulatory aspects and on confined or unconfined GM crop releases by means of electronic infrastructures such as the Web. Their aim is to assure regulatory transparency, allowing for stakeholder consultation. One of these authorities is the Canadian Food Inspection Agency (CFIA), which is responsible for the regulations on products derived from biotechnology, including modified crop plants. It assesses the potential risk of the adverse environmental effects of GMOs and authorizes import permits, confined trials, unconfined releases, and variety registrations. Information on these regulatory aspects and the approval of releases can be found in the website http://www.inspection.gc.ca/ english/sci/biotech/bioteche.shtml.

In Germany, in addition to the aforementioned BioSearch database, the Centre for Gene Technology provides information on contained use and field releases in Germany and in the EU, with a list of products placed on the market in the EU (http://www.rki.de/GENTEC/ GENENG/GENTEC_E.htm). Most of these website pages are in German only, with essential information on regulations and releases provided also in English, the latter in table format.

Within the website dedicated to biotechnologies, the Italian Ministry of Health has developed a searchable database (http://www.sanita.it/biotec/ogm/ricerca.asp) containing information on biotechnological products approved for experimental phase and field trials, and on companies or institutes carrying out the experimentations and their location. However, current field tests to obtain registration of new varieties or GM hybrid crops are not included in the database, and one must directly request the competent authority for related information. The language of the site is Italian only. It also dedicates some pages to other important links, to the taxonomy of GM plants and to the official documents of the EU Commission on the authorization for the commercialisation of GMOs within the EU.

In Japan, through its website http://www.s. affrc.go.jp/docs/sentan/index.htm, the Ministry of Agriculture, Forestry and Fisheries (the Innovative Technology Division), lists the available developing transgenic crops, specifying whether they have been approved for either field tests or general releases, and the current status of their commercialisation. The list table contains information on plant, variety or strain, developer, trait and 


\section{G. Degrassi et al.}

related gene, and status of approval (isolated or open field, import, food or feed use). The last updating of the list table of field tests and general releases goes back to July 2002, while that for commercialised transgenic crops was in March 2000.

Activities of certain national authorities not only address information on the regulations and releases of GM crop, but also on GM food. Health Canada is the Canadian governmental agency responsible for assessing food safety. In the case of novel foods, it considers the process used to develop the food, its characteristics compared to those of the traditional counterpart, and its toxicity and allergenicity according to the national "Novel Food Regulation". The sections of the website, http:// www.hc-sc.gc.ca/english/index.html, provide examples of and decisions on novel foods, as well as regulations and guidelines for safety assessments. Decision documents on novel food can be accessed from the corresponding section, providing detailed information on (i) how the modified plant was developed; (ii) gene products; (iii) changing of dietary exposure; (iv) analysis of nutrients; and (v) food safety in relation to potential toxicity and allergenicity.

In the USA, the leading country for the development and commercialisation of GMOs, the following three governmental agencies are involved in the regulatory framework for the agro-alimentary applications of biotechnology: the Animal and Plant Health Inspection Service (APHIS) of the USDA, the Environmental Protection Agency (EPA) and the Food and Drug Administration (FDA). APHIS is in charge of oversight of field trials, and issues the relevant authorizations for the environmental release of GMOs based on the experimental data provided by the applicant. Through the APHIS web services http://www.aphis.usda.gov/ppq/biotech/, regulations, permit application information, and the present status of biotech applications can be searched. EPA is the responsible authority for the development, commercialisation, distribution and assessment of pesticides, and defines the residual limits of these pesticides in crops. It plays a major role in assessing GMOs, classifying those that are pest- or insect-resistant among plant pesticides (http://www.epa.gov/pesticides/biopesticides/). On the other hand, the FDA is in charge of assessing GM food safety and provides a list of completed consultations on bioengineered foods (http://www.cfsan.fda.gov/ 1rd/ biocon.html). The table provides letters responding to submissions and final memoranda from the agency in full text form.

The national competent authorities provide information on regulations, releases and food safety, which is the most requested information by stakeholders. However, other initiatives are worthy of being cited for contributing to the dissemination of information and transparency, as well as for their potential in developing expertise. Within the EU, the European Commission, through the Joint Research Centre (JRC) in Ispra, Italy is elaborating on a core informatics activity to: (i) set up a database on analytical methods for detecting and quantifying DNA and protein; (ii) develop a molecular register of all DNA sequences of authorized GMOs, as well as the tools for analysis; and (iii) create a unique allergen database taking advantage of those already existing (Tab. 1). Further information on these and other biosafety activities of the Commission can be found on http://gmoinfo.jrc.it/.

Databases and other information-sharing tools have also been developed by non-governmental sources to address information needs of different user communities such as consumers, industry and universities. The longer the tradition for dealing with the environmental release and safety issues of GMOs, the greater the demand for information-sharing and thus the greater the number of relevant websites. One can have an idea of the abundance of these sites by visiting http://www.ejb.org/content/ vol3/issue1/full/2/appendix.html. Two non-governmental sources were found to be data-rich, well-structured and well-managed: Information System for Biotechnology (ISB, USA) and Agriculture \& Biotechnology Strategies (AGBIOS, Canada). The ISB website http:// www.nbiap.vt.edu/ provides information resources, documents and searchable databases pertaining to the development, testing and regulatory review of genetically modified plants, animals and microorganisms in the US and abroad. AGBIOS is a Canadian company dedicated to providing public policy, regulatory, and risk assessment expertise for biotechnology products. The AGBIOS "essential information" database (http:// www.agbios.com/main.php) contains a "crop database" on regulatory approvals for GMOs and novel foods; case studies to illustrate both environmental and food risk assessment for GMOs; a "bibliographic database" listing citations relevant to the environmental, human food, and livestock feed safety of GM crops (Tab. 1); and two examples of regulatory systems.

\section{OTHER DATABASES}

Although not specifically designed to address biosafety issues, a considerable number of databases contain potentially useful information in the decision-making process. Engines such as EMBL (http://www-db.embl- 
heidelberg.de/jss/SearchEMBL?services=x), SwissProt (http://www.expasy.org/), the National Center for Biotechnology Information (NCBI) (http://www.ncbi.nlm. nih.gov/About/index.html) and DNA Data Bank of Japan (DDBJ) (http://www.ddbj.nig.ac.jp/) provide access to sequence data and are thus crucial for the detection, identification, or risk assessment of GMOs. Similarly, there are numerous databases that address general toxicological issues (e.g. U.S. National Library of Medicine, http://www.toxnet.nlm.nih.gov/; FDA/CFSAN, The "Bad Bug Book", http://www.cfsan.fda.gov/ mow/ intro.html). Although they were not initially created to reflect potential toxicity resulting from a genetic modification, they are particularly relevant to food safety.

Patents represent another important source of information on different aspects of new biotechnology and could be an important tool in the decision-making process and risk assessment. In fact, the increasing use of intellectual property in Life Sciences results in a growing number of patents protecting the outcomes of new biotechnological R\&D, not only the product itself, but also biotechnological methods, new DNA constructs and processes for production of biological products, among others. Several on-line databases have been established to allow access to patent information. A specific website dealing with patents regarding new biotechnological products was created and updated from 1994 to 1996 and can be accessed at http://www.nal.usda.gov/bic/ Biotech_Patents/. It also offers links to other useful electronic resources for patent searchers, such as the DNA Patent Database (DPD) at http://dnapatents.georgetown. edu/, which allows free searching of full text and analysis of all DNA patents issued by the United States Patent and Trademark Office (PTO). This database enables users to search the full text of the patents and delimited fields. The DPD is being developed with a particular focus on issued claims to enable relevant empirical studies of actual DNA-based patents. Patents included in the DPD were identified by virtue of PTO classification and the presence of keywords such as "DNA" within the body of the patent.

Other patent databases, not specific for biotechnological products, have been developed worldwide, such as the Patent Cooperation Treaty (PCT) database http:// pctgazette.wipo.int/; the Intellectual Property Data Collection at the World Intellectual Property Organization (WIPO) http://ipdl.wipo.int/; the European Patent Office and its patent information service (allowing searches in European, PCT, Japanese and worldwide patents) (http:// ep.espacenet.com/); the Japanese Patent Office (http:// www.jpo.go.jp/); and the Canadian Patent Database at the Canadian Intellectual Property Office (CIPO) (http:// patents1.ic.gc.ca/intro-e.html).

Another source of data that could be used by scientists and risk assessors is related to the relevant number of GM crops specifically designed to be resistant to insects and to the role played by $B t$ toxin genes in the development of these GM crops: insect resistance conferred by $B t$ genes represents the second trait after herbicide tolerance in GM crops such as maize, cotton and potato. The ongoing discovery of new $\mathrm{Bt}$ toxin genes and the rapid accumulation of information on their insecticidal activities prompted the Canadian Forest Service to construct a relational database on $B t$ toxin specificity in order to make this information accessible in a searchable format (Tab. 1). The database is hosted at the website http:// www.glfc.forestry.ca/bacillus/ and the searching engine allows information retrieval on either bioassays of $B t$ toxins or toxin genes. The outcome of the search is a list table including the insect species used for the bioassay of the specified toxin, the method used for the bioassay and its result, and the bibliographic reference for each bioassay/toxin gene representing the source of the information provided.

\section{DISCUSSION AND CONCLUSIONS}

The recent trend in database development made it useful to review some key websites and databases representing useful tools for risk assessment and biosafety evaluation of products deriving from modern biotechnology, GM crops in particular. We have identified a number of information categories provided through the web: the major ones are regulations, environmental and commercial releases, food safety, nucleotide sequences and scientific literature. However, other sources of information can become potentially useful in the decision-making process regarding the use of GMOs, such as patent databases.

\section{Dissemination of information}

Scientific institutions, national authorities and international organizations are the main actors involved in the process of disseminating information or informationsharing. Scientific institutions are predominantly oriented towards setting up tools supporting research, development and application. They also aim at improving the understanding of risks by developing appropriate methodologies, techniques and protocols for assessing risks posed by GM crops and food. In contrast, the activities of national authorities are focused on guaranteeing the 


\section{G. Degrassi et al.}

transparency of the adopted regulation, its application and the status of GMOs approval within the national territory. On the other hand, with the contribution of the largest number of stakeholders, international organizations try to coordinate and harmonize regulations and guidelines and develop common standards and protocols for quantifying the environmental impact of GMOs. They are also active in setting up capacity-building initiatives, which are particularly important for emerging economies and developing countries. Some databases developed by scientific institutions have been analysed in scientific articles, as previously described. They mainly include information on DNA sequences commonly used in the development of transgenic organisms and on sequences of allergenic proteins for identification of potential allergens in GMOs, botanical information on transgenic crops, or decision support systems for risk assessment. However, there has been experimentation with some databases as frameworks for storage and retrieval of environmental releases records. These records seem to be the main subject of the databases established by national authorities: the countries that approved releases, either for field tests or commercial purposes, wish to inform the public on the number, type and location of the releases approved. In Europe, general information on environmental releases is often duplicated due to parallel activity of the competent authorities of the European Union and some of the European countries that are part of the EU. The website http://biotech.jrc.it/ hosts a detailed overview of the environmental releases in all the European countries since 1991 (and later for those countries that had not yet belonged to the EU), according to Directive 90/220/EEC. The national authorities often duplicate this information as well as that related to other European countries, as seen in the Belgian Biosafety Server and in the German Centre for Gene Technology sites. However, the language problem, which could represent a barrier to accessing information for local users, and the need of providing more complete data on releases encouraged national authorities to develop national databases.

International organizations' efforts in sharing information and knowledge and establishing regulatory frameworks in a harmonized and coordinated manner are evident from the many initiatives already existing or in progress. Different organizations have taken on the responsibility of various aspects of new biotechnology food and crops. Regulation development in biotechnology is globally monitored by BINAS (UNIDO); the record of new biotechnological products and field trials of GMOs is regularly updated by OECD; conservation and sustainable use of biodiversity is in the care of the
CBD Secretariat, which also promotes the adoption of the $\mathrm{CPB}$ to protect the environment. Through the Biosafety Clearing House, CPB is also working on tools for a facilitated exchange of information on GMOs. In addition, the UNEP is implementing projects for capacity-building in biosafety; FAO has some initiatives related to the safety of new food; and the ICGEB bibliographic database collects scientific literature on the biosafety of GMOs.

\section{Key information in biosafety}

As a consequence of the high number of applications for releasing or marketing transgenic plants and the consequent evaluation of the regulatory authorities in most countries, the number of risk assessment documents produced worldwide has become considerable and represents an important source of information in the decisionmaking process, as also stated in some CPB articles. Although international standardized schemes and test procedures in risk assessment have not been fully developed, the abundance of the documents produced at the national level calls for certain initiatives. These initiatives are aimed at facilitating access to existing documents, including those not yet available in electronic format. $\mathrm{BCH}$ is in the process of developing such a tool, which will be available in the Pilot Phase website as part of the communication and exchange of information between Parties requested to the $\mathrm{BCH}$ within the CPB. ICGEB has already established a searching mechanism for the storage and retrieval of risk assessment documents produced worldwide, including from those countries without electronic infrastructures, as previously explained. In this case and in all other situations when initiatives overlap and information is duplicated, coordination and collaboration are recommended.

The development of the central $\mathrm{BCH}$ database that collects and provides information on regulations, decisions documents and bibliography has raised the problem of interoperability between the central system and other databases supplying information. For this reason, interoperability protocols have been established in order to facilitate the development and maintenance of interoperable databases by either Parties or partners. Partners such as OECD with the BioTrack and Bioproducts databases, and ICGEB with the bibliographic database, have been requested to follow specific guidelines to enter into this information-sharing system. Other information will be made available by national focal points that have to satisfy the same requirements. In order to facilitate development of national databases compatible with the 
requirements of the centralised system, using a common database template has been proposed.

\section{Quality of information}

There is growing concern over the quality of information that is accessible on the Internet. Reliability and usefulness of the information in databases to be used in the decision-making process depend on validation, the process of confirming correctness. In this review, we have shown many databases providing information on a few key subjects such as regulations, releases, risk assessment, scientific literature, DNA sequences, and analytical methods. Information can be supplied in different ways: unmodified from the original source, revised, reduced, expanded or integrated with other data. This situation poses the problem of who is responsible for the validation. In regard to databases containing information on regulations, the regulatory authority is usually the reference for the quality of the input furnished. The BINAS database on regulatory issues in fact supplies links to national governmental web pages for laws, regulatory frameworks or guidelines, together with coordinates of the responsible ministry or agency. Scientific literature stored in and retrieved from databases is usually peerreviewed, as seen in the ICGEB bibliographic database, but not necessarily subject to quality assurance procedures (e.g. good laboratory practice), which limits the application of data contained. Similar considerations could be raised for information sources on risk assessment documents, environmental releases of GMOs approved for field tests or commercialisation, DNA sequences and analytical methods. For a database based on links, the information sources provided should be selected carefully to include trustworthy data only, usually from the original provider. The systems that allow submission of data usually identify the officially responsible authorities or persons as "focal points" $(\mathrm{BCH})$ or "contributors" (FAO Portal for food safety and plant and animal health) to guarantee the reliability and validation of the information disseminated. The information provided in each category needs to be complete and limited to well-defined time periods, and the level of detail provided should concur with the knowledge level of the expected users.

The organization or the experts behind the information resource should guarantee the reliability of the information provided and be available for clarification or updating with new information. The updating status is one of the problems regarding many websites, which is particularly important for databases. It would be advisable to ensure a correspondence between the date of the last updating (usually indicated on the home page) and the information contained in the database to ensure regular maintenance and stability of the electronic resource. Moreover, it should always be possible to identify the date to which the information can be referred.

\section{Coordination and harmonization of initiatives}

One of the criteria for the importance and relevance of database content is its uniqueness; however, the increasing number of existing databases increases the risk of duplicating information. Despite the redundant information available from different sources, there are advantages - different formats for users with different access requirements, easier access (through mirror sites) and complementary information or updating. In this respect, the establishment of the Inter-Agency Network for Safety in Biotechnology (IANB), chaired by OECD, is an attempt to consolidate international efforts in disseminating biosafety information. The following organizations are presently part of that network aimed at harmonizing and synergizing information-sharing initiatives: The Consultative Group on International Agricultural Research (CGIAR), CBD, ICGEB, FAO, Office International des Epizooties (OIE), OECD, United Nations Conference on Trade and Development (UNCTAD), UNEP, UNIDO, the World Health Organization (WHO) and the World Trade Organization (WTO). With respect to the high number of initiatives in progress, one should enquire into the reasons for setting up a database, ensuring that it is not to advertise or support a particular point of view.

\section{Accessibility of data}

In addition to their content, an important criteria that determines the usefulness of the biosafety databases is accessibility of information provided. Although Internet access is becoming more feasible and universal each year due to the invention, implementation and spread of novel technologies, free large-scale access still represents a problem in certain regions, especially in the developing world. For this reason, several biosafety database providers seek alternatives to Internet for the dissemination of information, such as printed or published materials (Zaid et al., 2001), diskettes or CD-ROMs (BCH, Agbios "Essential biosafety").

Another consideration of data accessibility is the language problem. This is especially valid for national 


\section{G. Degrassi et al.}

biosafety sites, which usually provide data in their original language - e.g. "BioSearch" (http://www.bba.de/) in German, CONABIA in Spanish (http://www.sagyp. mecon.gov.ar/), CTNBio (http://www.ctnbio.gov.br/ ctnbio/Default.htm) in Portuguese, and the Italian Ministry of Health (http://www.sanita.it/biotec/ogm/ricerca. asp) in Italian. Several national sources offer additional English versions (Belgian Biosafety Server). In principle, the international organizations try to permit searching in all the official languages of their member states (CBD, FAO).

As a general rule, a database should be organized for easy usage and user-friendliness. It is therefore advisable that special commands be clear, help information be available, and menu design and screen readability be appropriate. Searching and retrieval systems have to be efficient and their use, intuitive (Smith, 1997).

\section{CONCLUSIONS}

The importance of available databases relevant to modern biotechnology and biosafety is evident for many reasons, in particular for easy accessibility to the information provided. Taking into consideration the increasing number of websites, databases, decision-supporting systems and other internet-based tools as a consequence of the rapid development of the biotechnological industry, the need arises for putting additional efforts into a better classification of biosafety database resources and capable data management in order to extend their reliability, operability, accessibility and user-friendliness. Further steps towards consolidating and synchronizing these efforts are in progress at the international level, ensuring the active participation of all international organizations and instruments involved. Databases can be considered an important tool for developing three key subjects aimed at reducing the potential negative impact of the new biotechnological products: dissemination of information, capacity-building and transparency.

\section{ACKNOWLEDGEMENTS}

This work was partly supported by a contract (GMO RES COM, QLAM-2001-00037) from the European Community Quality of Life, 5th Framework Programme. We would like to thank Vittorio Venturi for helpful comments and revisions of the manuscript, and Francesca Farolfi for websites updating. N. A. is the recipient of a fellowship of the Italian Ministry for Environment, which also supported the development of the ICGEB Risk Assessment Searching Mechanism (RASM).

Received January 28, 2003; accepted June 26, 2003.

\section{REFERENCES}

Ahmed FE (2002) Detection of genetically modified organisms in food. Trends Biotechnol. 20: 215-223

Conner AJ, Glare TR, Nap JP (2003) The release of genetically modified crops into the environment. Part II. Overview of ecological risk assessment. Plant J. 33: 19-46

Croy RRD (1993) Plant selectable genes, reporter genes and promoters. In Croy RRD, ed, Plant molecular biology labfax, Bios Scientific Publishers, Oxford, UK, pp 149-182

Francisco M (1999) Biosafety and regulation. Nat. Biotechnol. 17: 89

Gendel SM (1998a) The use of amino acid sequence alignments to assess potential allergenicity of proteins used in genetically modified foods. Adv. Food Nutr. Res. 42: 45-62

Gendel SM (1998b) Sequence databases for assessing the potential allergenicity of proteins used in transgenic foods. Adv. Food Nutr. Res. 42: 63-92

Gliddon CJ, Rasch DAMK, Schmidt K, Schutte GAM, Sideridis AB, Yalouris CP (1997) A biometrical decision support system for estimating risk assessments on releasing genetically modified organisms. In Proceedings of the First European Conference for Information Technology in Agriculture. June 15-18, 1997, Copenhagen, Denmark

Havukkala I (1996) Transgenic rice and rice genome research. Field Crop Res. 45: 27-35

Hileman RE, Silvanovich A, Goodman RE, Rice EA, Holleschak G, Astwood JD, Hefle SL (2002) Bioinformatic methods for allergenicity assessment using a comprehensive allergen database. Int. Arch. Allergy Imm. 128: 280-291

James C (2002) Global status of commercialized crop: 2002. ISAAA: Ithaca, New York

Kirsop BH (1993) Development of the Information Resource for the Release of Organisms into the Environment. Biotechnology R\&D Trends - science policy for development. Ann. NY Acad. Sci. 700: 173-176

Landsmann J, Shah A (1995) BioSearch: GentechnikDatenbank der BBA, 3.Mitteilung. Nachrichtenblatt des Deuthschen Pflanzenschutzdienstes 47: 135

Louwaars N, Brandenburg W, Gilissen L, Kleter G, Wagenaar J (2002) The Biosafety Files, a new link in biosafety information. Biotechnol. Dev. Monit. 49: 13-14

Smith AG (1997) Testing the surf: criteria for evaluating Internet information resources. The Public-Access Computer Systems Review (http://info.lib.uh.edu/pr/v8/n3/smit8n3.html)

Zaid A, Hughes HG, Porceddu E, Nicholas F (2001) Glossary of biotechnology for food and agriculture. A revised and augmented edition of the Glossary of biotechnology and genetic engineering. Publishing and Multimedia Service, FAO, Rome, Italy 